\title{
Liberdade de expressão versus limites do humor: a constituição do ethos na polêmica
}

\author{
Ana Cristina Carmelino
}

\section{Retórica, dissenso e liberdade de expressão}

\begin{abstract}
Artórica, nos moldes aristotélicos, se apresenta como a arte de negociar as A diferenças para se chegar a um acordo. Logo, se instaura onde se tem uma questão controversa ou onde há mais de um ponto de vista sobre um assunto. Nessa proposta, aqueles que deliberam sobre um tema controverso devem apresentar argumentos racionais que permitam pesar sobre os prós e contras de cada tese, a fim de resolver o conflito e alcançar uma resposta comumente aceita. Embora a deliberação deva obedecer aos ditames da razão e, portanto, o trabalho com o logos, o ethos (a imagem que o orador constrói de si) e o pathos (a capacidade de despertar as emoções no auditório) têm sua contribuição.

Considerando-se que uma questão controversa pode gerar debate ou polêmica e que nem sempre é possível superar o conflito, Amossy ${ }^{1}$ reflete sobre como avançar os pressupostos da tradição aristotélica, levando-se em conta os casos em que não há acordo ou consenso. Para a autora, o espaço público consiste num campo de competição de interesses que tomam forma de conflitos que podem não levar a um acordo, ou seja, à constituição de
\end{abstract}

1 Amossy, 2017. 
um debate arrazoado como ideal de razão e de harmonia social, um meio prático de gestão democrática. Nesse sentido, propõe rever a polêmica na perspectiva da retórica, mostrando o impacto das concepções de conflito alicerçado no debate público.

O dissenso, conforme Amossy, nasce de situações tidas como polêmicas, aquelas oriundas do choque entre opiniões antagônicas, ligadas sobretudo ao desacordo. As situações polêmicas, vistas como modalidades argumentativas, devem configurar-se, no entanto, num ambiente democrático, em que o ethos dos oradores se ressalta sobremaneira para infundir conformações patéticas no interior de um auditório, quer seja ele particular quer seja ele universal. Partindo dessas considerações, neste texto pretendemos refletir sobre como o ethos é constituído na polêmica, mais precisamente sobre como a retórica do dissenso contribui para a consolidação do ethos.

A reflexão - fundamentada tanto por pressupostos da Retórica e da Nova Retórica, no que diz respeito ao conceito de ethos, quanto pelas modernas teorias argumentativas no que tange à noção de polêmica - toma como base, em termos metodológicos, um caso específico de situação polêmica ocorrido em abril de 2019 no Brasil: a condenação do humorista Danilo Gentili à prisão por ofensa a uma deputada. A ação traz em cena os limites do humor e coloca em discussão se deve ou não haver liberdade de expressão.

Para os propósitos deste texto, é, pois, na circulação de discursos que se constrói a polêmica como conjunto de confrontos verbais sobre uma questão social. No caso dos limites do humor, a questão é antiga. Cícero $^{2}$, na arte da oratória em que discutia o uso do humor (ou ridículo, termo empregado pelo autor) nos discursos públicos da antiguidade, já ressaltara que se o humor fosse malicioso, cruel com as deficiências alheias e não sopesasse o alvo da zombaria, o auditório e as circunstâncias do discurso, acabaria sendo desfavorável.

\section{Contextualização da polêmica: o caso Danilo Gentili}

Nascido em Santo André, SP, em 1979, Danilo Gentili Jr. tornou-se conhecido como humorista e apresentador de TV, mas também é ator,

2 Citemos aqui o capítulo que Cícero dedica ao riso e ao risível, que consta do segundo livro do $D e$ Oratore (55 a.C.), uma das principais fontes dos estudos sobre humor (cf. CICERÓN, 2002). 
escritor, cartunista, fotógrafo, repórter, publicitário e empresário brasileiro. Faz parte da considerada "nova geração do humor" e é reconhecido como um dos precursores e idealizadores do movimento do Stand-up Comedy no Brasil. Dentre os vários trabalhos exercidos por Gentili, destacam-se: nos palcos, os shows Danilo Gentili - Volume 1 e Politicamente Incorreto; na televisão, ganhou projeção nacional como repórter do programa humorístico CQC, exibido pela Band, apresentou Agora É Tarde (entre 2011 e 2013) e atualmente apresenta The Noite no SBT; no cinema, participou dos filmes Mato sem cachorro (2013), Superpai (2015) e em Como se tornar o pior aluno da escola (2017); como escritor, lançou os livros Como se tornar o pior aluno da escola (2009), Politicamente incorreto (2010), A vida e outros detalhes insignificantes (2012) e Droodles (2015), no qual incluiu os desenhos (droodles) que faz em um quadro de seu programa no SBT. Ainda atuou como cartunista e colunista da edição brasileira da revista humorística Mad, além de ter sido colunista do Metro Jornal (publicação impressa gratuita do Grupo Bandeirantes de Comunicação) e do Jornal da Manhã, noticiário matinal da rádio Jovem Pan³.

Conhecido também como um dos defensores ferrenhos de que o humor não deve ter limites - "O humor não tem limite. O que tem limite é a chatice, pessoa ficar magoadinha com piada é mau humor. Isso que deveria ter limite, não humor4"; "O limite do humor é quando o alvo da piada tira sua própria vida"; "Minha intenção com a comédia não é denunciar... é destruir mesmo5", "Se você não aguenta uma piada, foda-se" -, Gentili frequentemente envolve-se em polêmicas por conta do teor provocativo de seu humor, seja por frases ditas em seu programa ou shows de comédia, seja por opiniões ou piadas postadas em suas redes sociais ${ }^{6}$. Para muitos, no entanto, a sua forma de fazer humor esbarra entre o engraçado e o ofensivo.

Em 10 de abril de 2019, Gentili foi condenado, em primeira instância, a seis meses e 28 dias de prisão em regime semiaberto por crime de injúria contra a deputada federal Maria do Rosário (PT-RS) ${ }^{7}$. O caso teve início em março de 2016, quando o apresentador publicara em sua conta no Twitter

3 As informações constam no Facebook de Danilo Gentili (https://www.facebook.com/pg/Danilo.Gentili.Oficial/about/?ref=page_internal) e na Wikipédia (https://pt.wikipedia.org/wiki/Danilo_Gentili).

4 Gentili, Facebook, 17 dez. 2012.

5 O riso dos outros, 2012.

6 Para ilustrar algumas das polêmicas em que Gentili esteve envolvido, veja-se: https://www.desafiomundial. com/as-vezes-que-danilo-gentili-exagerou-nas-piadas-e-causou-muita-polemica/?view-all\&chrome $=1$.

7 A sentença sobre a condenação de Danilo Gentili pode ser consultada, na íntegra, em: http://www.jfsp. jus.br/documentos/administrativo/NUCS/decisoes/2019/2019-04-10-condenacaodanilogentili.pdf. 
mensagens em que chamava a parlamentar de "cínica, falsa e nojenta", por conta de acusar Gentili de fazer piadas machistas, mas aprovar a atitude do ator José de Abreu de cuspir em casal que jantava em um restaurante em São Paulo por criticá-lo por causa da Lei Rouanet ${ }^{8}$.

Após receber uma notificação extrajudicial enviada por advogados da deputada pedindo que as mensagens ofensivas fossem apagadas, Gentili gravou um vídeo em que abre a notificação, esconde com os dedos o início e o fim da palavra "deputada", deixando apenas o meio, "puta", visível. Em seguida, rasga o documento, esfrega os pedaços de papel dentro de sua calça e dá a entender que os remeteria de volta à Câmara dos Deputados'. Tal atitude levou Maria do Rosário a requerer a condenação dele por injúria, a qual foi acatada pela juíza federal Maria Isabel do Prado, da 5a Vara Federal Criminal de São Paulo.

A principal linha de argumentação da defesa de Gentili, segundo seu advogado, Rogério Cury, é que ele não teve a intenção de humilhar a deputada e, portanto, deveria ser absolvido do crime de injúria. Na fala de Cury, "ele quis fazer um comentário humorado. Temos que diferenciar humor mais ácido de crime [...]. A fala do Danilo é de cunho humorístico e crítico, mas ele nunca teve a intenção de praticar crime. Ela [Maria do Rosário] pode não ter gostado, mas daí a dizer que ele cometeu um crime, a distância é muito grande $^{10}$. A defesa de Gentili sustenta que a decisão atinge a liberdade de expressão e criminaliza o humor.

$\mathrm{Na}$ decisão que condenou Gentili, a juíza considerou que o humorista ultrapassou os limites da ética e da liberdade de expressão e, por isso, tratou-se de um crime de injúria. Na sentença, ressalta o direito à liberdade de expressão, mas pontua que quando alguém ultrapassa a linha da ética, "surge no Estado de Direito a tutela penal como legítimo instrumento de contenção contra o uso abusivo da liberdade de expressão ${ }^{11}$ ". A magistrada não acatou os argumentos de Gentili de que não houve dolo em ofender a honra ou a dignidade por se tratar de uma peça humorística, ao contrário; "não contente com a injúria propalada, resolveu gravar um vídeo com conteúdo altamente ofensivo e reprovável, deixando muito clara a sua intenção de ofender ${ }^{12}$."

8 Maiores informações sobre o caso, confira Maynard (23 abr. 2016).

9 O vídeo, divulgado por Gentili em junho de 2017, está disponível em: https://www.youtube.com/ watch? $\mathrm{v}=\mathrm{kaLZaRRvxtE}$.

10 Cf. Tavares, 12 abr. 2019.

11 Pereira, 16 abr. 2019.

12 Mazzoco, 10 abr. 2019. 
A notícia da condenação levou a opinião pública, constituída de discursos autorizados ou correntes sobre o assunto (advogados, humoristas e leitores de textos sobre o ocorrido), a opinar e a se posicionar sobre o caso - seja quanto à atitude de Gentili (saudada ou criticada), seja quanto à pena aplicada (vista como adequada ou indevida). Como observa Amossy ${ }^{13}$, as polêmicas invadem o espaço público, ocupam, portanto, posição privilegiada as mídias das quais se nutre a opinião. $\mathrm{O}$ ocorrido não apenas disparou uma discussão nas redes sociais, onde o apresentador é bastante ativo, mas, também, retomou o debate sobre censura versus liberdade de expressão quanto à questão da produção de humor. Nesse sentido, o questionamento que esteve no cerne do dissenso foi: o que vem primeiro, liberdade de expressão ou o respeito à honra de uma pessoa?

\section{O humor e o dissenso: censura versus liberdade de expressão}

O olhar sobre o humor, especialmente no que diz respeito a sua expressão e função, sempre dividiu opiniões. Skinner, em resumo sobre como o humor/ riso foi entendido e apreciado por diferentes pensadores ao longo da história, registra que é possível depreender pontos de vista positivos e negativos sobre o tema. No primeiro caso, o fenômeno é tido como "expressão pura de alegria e prazer ${ }^{14}$ ", elemento leve da vida; forma de preservar a saúde (discurso médico, baseado na teoria dos humores), de evitar a melancolia; um meio de ser civilizado; algo digno de ser encorajado, mesmo como expressão de escárnio, para reprovar vícios. É pelo humor que críticas veementes conseguem ser feitas (quem podia fazer gracejos e indicar defeitos do rei? - o bobo da corte). No segundo caso, o humor é visto como objeto de reprovação; logo, algo que deve ser evitado. As razões para isso são várias: escarnecer dos outros (em especial das fraquezas alheias, dos defeitos naturais que não podem ser corrigidos) é algo indigno, sinal de pusilanimidade; zombar em demasia é agir de forma ilícita; rir é antissocial, deselegante, grosseiro (tanto no sentido de incivilidade quanto de indelicadeza), indecoroso, "é algo baixo e inconveniente ${ }^{15}$ ".

13 Amossy, 2017.

14 Skinner, 2002, p. 65.

15 Ibid., p. 74. 
Enfim, se a crítica social feita pelo humorista pode tocar em assuntos difíceis, é algo que deve ser valorizado. Por outro lado, não é fácil a tarefa de se constatar se/quando o humorista age de forma adequada ou ultrapassa a barreira do aceitável. Há uma linha tênue, vista muitas vezes de forma subjetiva, entre arte (legal) e ofensa (ilegal), que faz com que as pessoas divirjam sobre a questão. Como usar o humor na medida certa? É possível? É preciso? Qual seria o limite da respeitabilidade? Trata-se, portanto, de assunto controverso, polêmico, que põe em xeque os limites do humor.

Concebida como "um debate em torno de uma questão de atualidade, de interesse público, que comporta os anseios das sociedades mais ou menos importantes numa dada cultura ${ }^{16}$, a polêmica tem como marca a oposição de discursos. Nesse sentido, uma situação de dissensão, de confrontação, coloca dois discursos em presença e, portanto, em relação, permitindo assim uma apreciação por comparação. Na verdade, como assevera a autora, a polêmica significa "um debate que permite a cada um expor e defender seu ponto de vista, frente aos pontos de vista comparados dos outros participantes ${ }^{17}$.

Tomando como base os pressupostos de Amossy ${ }^{18}$ sobre o dissenso, que funciona no nível discursivo-argumentativo, para refletir sobre a polêmica instaurada quanto aos limites do humor, é possível considerar no choque de opiniões contraditórias "uma dicotomização na qual duas opções antitéticas se excluem mutuamente", seriam dois modos de ver: a posição de que o "humor deve ser livre" (caracterizado pelo discurso sobre "liberdade", direito de falar o que quiser, mesmo que se trate de discursos agressivos) e o posicionamento de que o "humor deve ter limites" (caracterizado pelo discurso sobre "limite", deve ter censura, podendo-se punir quem os ultrapasse). Desse modo, os defensores da "liberdade de expressão" leem qualquer argumento que proponha qualquer restrição ao discurso não como limite, mas como "censura". Já os defensores do "limite" leem qualquer argumento do outro discurso não como "liberdade", mas como "abuso" (que se configura como "desrespeito", "grosseria", "falta de educação", "falta de sensibilidade").

Amossy, 2017, p. 49.

Ibid., p. 49.

Ibid., p. 53. 


\section{A constituição do ethos na polêmica}

O conceito de ethos, visto especialmente no campo da retórica, suscita uma discussão que perpassa séculos, considerando-se como o termo era visto e trabalhado na Filosofia antiga até frequentes releituras feitas em décadas mais recentes. Embora Aristóteles não tenha sido o primeiro a cunhar a noção na retórica, pode-se dizer que foi quem delineou as premissas nucleares de como o ethos viria a ser trabalhado. Para Aristóteles ${ }^{19}$, os discursos acionam um tripé de elementos constituintes. O primeiro seria o do orador, que mobilizaria a dimensão do ethos. Este seria a imagem que o orador projeta de si, em seu discurso, para convencer e persuadir seu auditório, seja ela verdadeira ou não. $\mathrm{O}$ segundo elemento seria o pathos, aspecto centrado no auditório e nas emoções por ele manifestadas (mas que são incitadas pelo orador). $\mathrm{O}$ terceiro diz respeito ao logos, que se centra na argumentação utilizada (na produção do discurso em si).

De acordo com os pressupostos aristotélicos, o ethos - uma das provas que tornam o discurso persuasivo - liga-se a um conjunto de traços de caráter que o orador mostra ao auditório para dar boa impressão. Os traços fundamentais (ou disposições) para inspirar a confiança no orador seriam: a) a prudência (phrónesis), b) a virtude (areté), c) a benevolência (eúnoia). A esse respeito, Fiorin ressalta, com base nos escritos aristotélicos, que os três casos conotariam, respectivamente:

a) a phrónesis, que significa o bom senso, a prudência, a ponderação, ou seja, que indica se o orador exprime opiniões competentes e razoáveis; b) a areté, que denota a virtude, mas virtude tomada no seu sentido primeiro de "qualidades distintivas" do homem (latim uir, uiri), portanto, a coragem, a sinceridade; nesse caso, o orador apresenta-se como alguém simples e sincero, franco ao expor seus pontos de vista; c) a eúnoia, que significa a benevolência e a solidariedade; nesse caso, o orador dá uma imagem agradável de si, porque mostra simpatia pelo auditório. O orador que se utiliza da phrónesis se apresenta como sensato, ponderado e constrói suas provas muito mais com recursos do lógos do que com os do páthos ou do éthos (em outras palavras, com os recursos discursivos); o que se vale da areté se apresenta como desbocado, franco, temerário e constrói suas provas muito mais com os recursos do éthos; o que usa a eúnoia apresenta-se como alguém solidário com seu enun-

19 Aristóteles, 2015. 
ciatário, como um igual, cheio de benevolência e de benquerença e erige suas provas muito mais com base no páthos ${ }^{20}$.

Revisitado contemporaneamente pela corrente teórica da Nova Retórica, o conceito de ethos passa a ser visto de forma ampliada e ressignificada. Quanto à definição, trata-se da "imagem que o orador constrói de si e dos outros no interior do discurso ${ }^{21}$ ". Perelman e Olbrechts-Tyteca ${ }^{22}$ inserem a atividade discursiva, e seus integrantes, na equação definidora do ethos. Desse modo, o orador passa a moldar sua fala conforme os valores que ele crê valorizados por seu auditório.

Para $\mathrm{Meyer}^{23}$, não se pode identificar o uso da palavra ethos, pura e simplesmente, ao orador, visto que se trata de algo mais complexo: "ethos é um domínio, nível, uma estrutura". Nesse sentido, "não se limita àquele que fala pessoalmente a um auditório, nem mesmo a um autor que se esconde atrás de um texto". Segundo o filósofo belga, que vê a noção sob a ótica da problematologia, o ethos se apresenta "como aquele ou aquela com que o auditório se identifica, o que tem como resultado conseguir que suas respostas sobre a questão tratada sejam aceitas". O teórico ainda propõe uma distinção entre o que chama de ethos projetivo e ethos efetivo: o ethos imanente ou projetivo corresponde à "projeção da imagem que deve ter o ethos aos

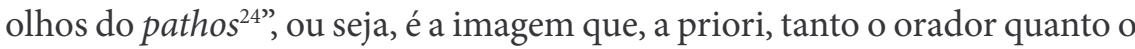
auditório projetam entre si; já o ethos efetivo, ou não-imanente, diz respeito à imagem realmente construída pelo orador, visando persuadir o auditório, a que seria, portanto, efetiva.

Ao retomarmos o caso Danilo Gentili - mais precisamente a notícia de sua condenação, que mobilizou diferentes posicionamentos não só sobre a pena aplicada ao humorista (que gera o debate sobre censura e liberdade de expressão), mas também sobre o seu comportamento -, verificamos que a constituição do ethos do humorista mostra-se polemizada. Levando-se em conta que a polêmica permite a cada um expor e defender seu ponto de vista, frente aos pontos de vista comparados dos outros, vejamos alguns comentários que circularam na Internet após a decisão judicial, para mostrar a instauração do dissenso.

20 Fiorin, 2015, p. 71.

21 Ferreira, 2010, p. 90.

22 Perelman e Olbrechts-Tyteca (1996)

23 Meyer, 2007, p. 35.

24 Meyer, 2007, p. 35. 


\section{1) Danilo Gentili, dois dias após a notícia da condenação, em entrevista no Pânico (12 abr. 2019) ${ }^{25}$}

"É praticamente impossível que eu seja preso, porque cabe recurso e tudo mais, mas há uma semana atrás, se você me perguntasse se eu seria condenado por protestar, eu diria que seria praticamente impossível... então vai saber..."

"Ainda que eu vá preso, eu prefiro ir preso a me ajoelhar para a patrulha [...] Eu não acho que fiz nada de errado. Às vezes é uma obrigação desrespeitar a patrulha e o autoritarismo [...] Essa classe política é autoritária e usa a máquina estatal para esmagar o cidadão [...] Eles falam o que querem, quando a gente responde, é condenado à prisão"

Os enunciados partem de um orador que tem discurso autorizado, já que se trata um humorista reconhecido falando sobre o ocorrido em programa de rádio com certa repercussão nacional. Do logos, é possível depreender diferentes ethé construídos pelo próprio orador em sua enunciação, como é o caso de conhecedor da situação ("praticamente impossível que eu seja preso... cabe recurso"), convicto/rebelde ("prefiro ir preso a me ajoelhar para a patrulha"), inocente ("não fiz nada de errado"), crítico/provocador ("é uma obrigação desrespeitar a patrulha e o autoritarismo") e indignado ("quando a gente responde, é condenado à prisão").

No que concerne às disposições, vistas em Aristóteles e Fiorin, que tornam os oradores persuasivos a partir das imagens que exibem, verificamos que Gentili manifesta um ethos de areté, uma vez que se mostra franco ao expor seus pontos de vista, apresentando-se como desbocado e temerário. Ao se pronunciar, visando justiça, busca incitar no auditório a compaixão, manifestando impudência e indignação ${ }^{26}$.

25 As informações podem ser conferidas em: https://www.youtube.com/watch?v=5tHBnMZRmPk

26 Para maior aprofundamento das paixões mencionadas, pode-se consultar Aristóteles (2003). 


\title{
2) Maria do Rosário, no dia em que saiu a decisão da condenação, em seu Twitter ${ }^{27}$
}

\begin{abstract}
"A condenação do Sr. Danilo Gentili deve ser lida como uma convocação à sociedade para retomar o respeito, o bom senso no debate público, nas redes sociais e na vida. Compartilho trecho da sentença. [...]. Considero a decisão um símbolo de que é possível preservar a liberdade de expressão e garantir a dignidade humana. Esta é uma vitória da democracia e da justiça"
\end{abstract}

O discurso da deputada, também autorizado, mostra Danilo Gentili culpado ("A condenação do Sr. Danilo Gentili... é uma vitória da democracia e da justiça"), logo, constrói para ele os ethé de desrespeitoso e de sem bom senso/ provocador ("a condenação deve ser lida como uma convocação à sociedade para retomar o respeito, o bom senso no debate público"). Por valer-se da decisão judicial para manifestar sua opinião sobre o caso nas redes sociais, a oradora manifesta um ethos que ressalta a phrónesis, apresentando-se como sensato e ponderado a partir de recursos do logos.

\section{3) Manifestantes diversos}

Nesse caso, podemos depreender três posicionamentos sobre o acontecido:

a) contrários à condenação de Gentili (e a favor da liberdade de expressão), independentemente do comportamento do humorista

"Me solidarizo com o apresentador e comediante Danilo Gentili ao exercer seu direito de livre expressão e sua profissão, da qual, por vezes, eu mesmo sou alvo, mas compreendo que são piadas e faz parte do jogo, algo que infelizmente vale para uns e não para outros" - Jair Bolsonaro, atual presidente do Brasil ${ }^{28}$

"O que me preocupa é a questão de fundo, que é a liberdade de expressão e manifestação. Quando a Maria do Rosário interpela o

27 As informações podem ser conferidas em: https://www1.folha.uol.com.br/ilustrada/2019/04/danilogentili-e-condenado-por-injuria-a-deputada-maria-do-rosario.shtml. Acesso em: 20 set. 2019.

28 Tavares, 12 abr. 2019. 
Danilo, ela está se manifestando contra esses valores. Ela tem que entender que é uma pessoa pública e que a piada ou chiste não foi por causa da pessoa física, mas da jurídica' [...] essa questão da injúria é relativa: você pode dar bom dia para mim e eu interpretar como sendo algo irônico, querendo me sacanear" - Marcelo Madureira, do grupo Casseta \& Planeta $^{29}$

"O político tem imunidade parlamentar, não pode ser processado, e o comediante ou jornalista fica numa posição muito desfavorável. Um episódio desse me deixa perplexo [...] A deputada teria razão em acionar Gentili na esfera civil (o que de fato fez), mas processá-lo na área criminal demonstra uma desproporção de uso da força que se torna intimidatória [...] Eu respeito o Danilo, mas, para mim, não é [fazer] a defesa de uma pessoa, é a defesa de um estado de coisas que quem preza pela liberdade não pode tolerar" - Marcelo Tas, trabalhou com Gentili no CQC, da Band ${ }^{30}$

“De um lado, uma 'vítima' que goza de imunidade parlamentar, e que pode falar o que bem entender (e inclusive ameaçar cidadãos fazendo uso da máquina pública) sem sofrer qualquer retaliação. Do outro lado, um 'agressor' agora submetido a uma penalidade flagrantemente desproporcional por ter simplesmente feito chacota ácida a uma parlamentar que o ameaçava de censura utilizando-se da máquina estatal. Pelo bem da liberdade de expressão, que essa condenação seja revertida!" - Christian Costa Batagelo, leitor ${ }^{31}$

Nos discursos acima, observa-se que os oradores, em geral, demostram solidariedade a Gentili. Desse modo, valem-se - considerando-se os traços fundamentais para inspirar a confiança segundo Aristóteles - de um ethos que põe em relevo a eúnoia: apresentam-se como alguém solidários com o outro, como iguais (especialmente os humoristas), cheios de benevolência e tolerância, erigindo, portanto, suas provas muito mais com base no pathos; mostram-se preocupados em despertar no auditório a paixão da compaixão 
para com o humorista pelo ocorrido, isto é, um sentimento de pesar que recai sobre quem não o merece $e^{32}$.

A favor da liberdade de expressão, os oradores ressaltam o ethos profissional de Danilo Gentili, de humorista, que tem a prática do humor como um dos ofícios. O profissional do humor - visto como "aquele que, em seus ditos, escritos, desenhos, interpretações cênicas etc., manifesta humor" ou "pessoa que se dedica ao humor numa ou mais formas de expressão artística, como ofício" - pode lutar, como ressalta Possenti ${ }^{33}$, "permanentemente para que nenhuma proibição ou controle possa atingir suas produções" e tentar "fugir do controle do politicamente correto, justificando-se exatamente com base em certa concepção ou defesa de funções e práticas específicas que caracterizariam o campo humorístico". Nesse caso, os oradores dos discursos acima trazem à cena o ethos projetivo ou imanente proposto por Meyer ${ }^{34}$, uma vez que buscam projetar a imagem que deve ter o ethos de Gentili (de profissional do humor, que defende que o humor não deve ter limites) aos olhos do pathos ou auditório.

b) contrários à condenação de Gentili, mas com ressalvas a seu comportamento

"Acho que o vídeo do Danilo é de péssimo gosto, agressivo, desrespeitoso, infantil, sem graça, equivocado. Mas daí a ele ser preso por mandar uma pessoa enfiar um papel no cu, acho bastante autoritário e arbitrário, perigoso inclusive [...] todo mundo tem o direito de acionar a Justiça se se sentir ofendido com uma piada, mas a decisão abre um precedente grave, que pode atingir outros artistas, e estabelece uma pena exagerada" - Fábio Porchat, humorista, foi apresentador na Globo e Record e hoje está no canal GNT ${ }^{35}$

"Acho lamentável essa decisão. É uma pena que a Justiça legisle sobre a honra. Não acredito que ofensa seja crime nem que dê para legislar sobre o que ofende ou fere a honra de alguém ou não [...] Isso me lembra aquela antiga lei da legítima defesa da honra, que

32 Cf. Aristóteles, 2003.

33 Possenti, 2014, p. 27.

34 Meyer, 2007.

35 Tavares, 12 abr. 2019. 
era quando o homem matava a mulher adúltera e achava-se que ele tinha esse direito [...] Acho lamentáveis também as piadas que o Danilo fez com a Maria do Rosário, com a [deputada] Sâmia Bomfim, com as mulheres de um modo geral. Isso é extremamente deselegante e muito pouco engraçado mesmo. Mas falta de graça, para mim, não é crime. Falta de talento tampouco" - Gregorio Duvivier, apresentador do "Greg News", na HBO, e integrante do Porta dos Fundos, canal no YouTube ${ }^{36}$

Ao se manifestarem sobre o caso, os oradores com discurso autorizado revelam tanto os aspectos da eúnoia na constituição do ethos quanto características conceituais ligadas à areté, uma vez que se mostram solidários no que diz respeito à aplicação indevida da pena a Gentili - "a decisão abre um precedente grave, que pode atingir outros artistas, e estabelece uma pena exagerada" (Porchat); "Acho lamentável essa decisão. É uma pena que a Justiça legisle sobre a honra. Não acredito que ofensa seja crime nem que dê para legislar sobre o que ofende ou fere a honra de alguém ou não" (Duvivier) bem como francos ao exporem seus pontos de vista sobre a atitude de Danilo Gentili, considerada lastimável. Neste caso, ao transpormos as características do vídeo ou das piadas (destacadas por Porchat e Duvivier) a seu responsável (Danilo Gentili), as imagens desveladas para o humorista seriam, no geral, negativas, visto que o mostram como agressivo, desrespeitoso, infantil, sem graça, equivocado e deselegante.

c) favoráveis à condenação de Gentili e contrários a seu comportamento

"A sentença está tecnicamente correta e apenas faz valer a previsão legal de que abusos da liberdade de expressão sejam punidos a posteriori. A liberdade de expressão foi garantida ao Danilo, tanto que ele fez o que fez. Não concordo com o discurso de que uma decisão como essa cria autocensura, censura futura para outros casos. Todos têm que ser responsabilizados por seus atos" - Marina Pinhão Coelho Araújo, advogada e doutora em direito penal pela Faculdade de Direito da USP e professora do Insper ${ }^{37}$ 
"Sinceramente, acho que essa decisão fez muito bem em condenar e demonstrar que não se deve aceitar, numa sociedade minimamente civilizada, esse tipo de barbárie verborrágica [...] Ninguém pode, a título de fazer piada, se especializar na arte de ofender pessoas" - Fernando Castelo Branco, professor consultado pela Folha ${ }^{38}$

"Ele não tem talento nem pra ator nem humorista. Suas piadas de péssimo gosto e ofensas cotidianas agradam a uma faixa de público que por vários motivos são como ele e pensam como ele. Acho que a pena é justíssima e deveria ser agravada com uma multa financeira de 500 mil reais pela falta de talento, de humor e oportunismo" - Robson Jose de Oliveira, comentário de leitor ${ }^{39}$

Os discursos dos oradores que compõem este grupo defendem a aplicação da pena a Danilo Gentili: "A sentença está tecnicamente correta e apenas faz valer a previsão legal de que abusos da liberdade de expressão sejam punidos a posteriori ", "essa decisão fez muito bem em condenar" e "a pena é justíssima”. Desse modo, além de culpado, alguém que deve pagar pelos seus atos inadequados ou excessivos, desvelam para o humorista os ethé de grosseiro ("não se deve aceitar ... esse tipo de barbárie verborrágica") e ofensivo ("Ninguém pode, a título de fazer piada, se especializar na arte de ofender pessoas"). Respaldando a opinião na decisão judicial, observa-se que tais oradores manifestam um ethos de phrónesis e areté, uma vez que se apresentam como sensatos (não questionam a lei) e francos.

Ainda que a noção de ethos esteja ligada a um conjunto de traços de caráter que o orador mostra ao auditório para dar boa impressão, é preciso ressaltar que, numa dependência direta dos valores do auditório, a impressão "boa/positiva" ou "má/negativa" pode sofrer oscilações de sentido. Em retórica, não importa se o orador é ou não sincero, pois a eficácia do ethos é distinta dos atributos reais de quem assume o discurso. Há, no reconhecimento do ethos por um auditório, uma dinamicidade natural de confiança ou desconfiança, que ganha corpo à medida que se desenvolve o movimento discursivo. 
O auditório, durante um ato retórico, age estrategicamente para dirigir e autorregular o plano da credibilidade que pode atribuir ao orador. Nessa perspectiva, as representações de mundo, a imagem prévia do locutor construída no imaginário social, a autoridade institucional angariada e a imagem de si projetada na construção discursiva contribuem para a consolidação do ethos do orador ${ }^{40}$. Nas situações públicas e conflitivas, o ethos se infiltra pelos diversos discursos e se mostra de muitas formas, como pudemos ver. Visto na polêmica, consolida-se também como polêmico. Embora pareça óbvio dizer isso, o óbvio, às vezes, precisa ser explicitado.

Pode-se, contudo, dizer que a polêmica instaurada no caso em análise ser favorável ou ser contrário à condenação de Danilo Gentili, que retoma o dissenso censura versus liberdade de expressão quanto à produção de humor - permite observar que os discursos se constroem em torno de "desacordos fundamentais", seja quanto ao que é racional, evidente, demonstrável, cognoscível, seja quanto ao que é passional, porque não há como assegurar um modo de coexistência numa sociedade dividida entre posições e interesses divergentes. Nesse sentido, embora o consenso esteja longe de ser estabelecido, é preciso considerar que a polêmica tem um papel social importante: busca gerir o conflito e modelar a comunicação no nível discursivo argumentativo.

\section{Considerações finais}

Partindo do pressuposto que para entender a constituição discursiva do ethos numa situação polêmica é preciso vê-la em casos concretos, este texto buscou observar a constituição do ethos de Danilo Gentili - não apenas a partir de seu discurso, mas, sobretudo, dos discursos dos outros (pathos) após a notícia de sua condenação à prisão por ofensa a uma deputada, ação que trouxe em tela o debate sobre limites do humor e liberdade de expressão.

A proposta era refletir sobre como a retórica do dissenso contribui para a consolidação do ethos. No caso público e conflitivo em questão, observa-se que o ethos se mostra de muitas formas, consolidando-se, portanto, como polêmico. Desse modo, Danilo Gentili é mostrado ora como inocente (quando se leva em conta que usar do humor, mesmo que de forma ácida, grosseira,

40 Cf. Ferreira, 2010. 
ofensiva, não é crime) ora como culpado (quando se entende que o abuso da liberdade de expressão, ou seja, a falta de limites no humor é crime). Os diferentes ethé desvelados pelo ou para o humorista são vários: de um lado, convicto, crítico, profissional; do outro, desrespeitoso/ofensivo, provocador, equivocado, infantil, deselegante, agressivo.

A discussão que põe em xeque os limites do humor, como dito, é antiga e controversa. Grandes pensadores, como Cícero ${ }^{41}$, alertaram que o humor consiste num expediente que precisa ser ajustado à situação, à causa e ao auditório, sendo, assim, importante que o orador não ataque as pessoas que são caras aos ouvintes e que restrinja o uso do ridículo aos assuntos que não despertam intensa rejeição ou grande piedade. A condenação de Gentili mostra que sua fala e atitude de cunho humorístico e crítico, conforme ele mesmo alegou, foram interpretadas como fora da medida, do limite. Mas como falar em limite do humor para quem o humor não tem limite?

Embora a retórica, segundo os pressupostos aristotélicos, busque o consenso ou o acordo razoável, vemos que nas situações polêmicas, caracterizadas sobretudo num campo de competição de interesses, o acordo está longe de ser possível. No que tange ao debate incitado pela condenação de Gentili, observa-se uma dicotomização sobre o modo de ver a questão que se resume em "o humor deve ser livre" versus "o humor deve ter limites". Ainda que não haja consenso, é preciso considerar, juntamente com Amossy ${ }^{42}$, que "a polêmica preenche funções sociais importantes, precisamente em razão do que é em geral criticado nela: uma gestão verbal do conflito realizada sob o modo da dissensão".

\footnotetext{
41 Cícero, 2002.

42 Amossy, 2017, p.12.
} 


\section{Referências}

AMOSSY, R. Apologia da polêmica. Trad. de M. M. Cavalcante e R. B. W. S. Pinto. São Paulo: Contexto, 2017.

ARISTÓTELES. Retórica. Trad. de M. A. Júnior, P. F. Alberto e A. N. Penal. São Paulo: Folha de S.Paulo, 2015.

ARISTÓTELES. Retórica das paixões. São Paulo: Martins Fontes, 2003.

O RISO dos outros. Direção e roteiro de Pedro Arantes. Documentário. São Paulo, TV Câmara 2012. (50 min.)

CICERÓN, M. T. Sobre el orador. Madrid: Gredos, 2002.

DANILO Gentili é condenado por injúria contra deputada Maria do Rosário. Folha de S.Paulo, 10 abr. 2019. Disponível em: https://www1.folha.uol.com.br/ilustrada/2019/04/danilogentili-e-condenado-por-injuria-a-deputada-maria-do-rosario.shtml. Acesso em: 20 set. 2019.

D’LÍRIO, D. Danilo Gentili é condenado por injúria contra deputada Federal Maria do Rosário, Jusbrasil, abr. 2019. Disponível em: https://davilirio15.jusbrasil.com.br/noticias/697181891/ danilo-gentili-e-condenado-por-injuria-contra-deputada-federal-maria-do-rosario. Acesso em: 20 set. 2019.

FERREIRA, L. A. Leitura e persuasão: princípios de análise retórica. São Paulo: Contexto, 2010.

FIORIN, J. L. Argumentação. São Paulo: Contexto, 2015.

GENTILI, D. Facebook, 17 dez. 2012. Disponível em: https://www.facebook.com/Danilo. Gentili.Oficial/posts/399460303463863/

MAYNARD, R. José de Abreu cospe na cara de casal após provocação. Gazetaweb, 23 abr. 2016. Disponível em: https://gazetaweb.globo.com/portal/noticia.php?c=8531. Acesso em: 20 set. 2019.

MAZZOCO, H. Danilo Gentili é condenado à prisão por ofender a petista Maria do Rosário. O tempo, 10 abr. 2019. Disponível em: https://www.otempo.com.br/o-tempo-contagem/ danilo-gentili-e-condenado-a-prisao-por-ofender-petista-maria-do-rosario-1.2166444. Acesso em: 20 set. 2019.

MEYER, M. A retórica. Trad. de M. N. Pires. São Paulo: Ática, 2007.

PERELMAN, C.; OLBRECHTS-TYTECA, L. Tratado da argumentação: a nova retórica. São Paulo: Martins Fontes, 1996.

PEREIRA, J. Gentili faz piada com prisão e pede a humoristas: 'Não me defendam', Uol, 16 abr. 2019. Disponível em: https://f5.folha.uol.com.br/celebridades/2019/04/gentili-faz-piadacom-prisao-e-pede-a-humoristas-nao-me-defendam.shtml. Acesso em: 20 set. 2019.

POSSENTI, S. O humor é um campo. In: POSSENTI, Sírio. Cinco ensaios sobre humor e análise do discurso. São Paulo: Parábola, 2018. p. 11-40.

SKINNER, Q. Hobbes e a teoria clássica do riso. São Leopoldo: Editora UNISINOS, 2002. (Coleção Aldus).

TAVARES, J. Caso Danilo Gentili mobiliza humoristas e gera debate sobre liberdade de expressão. Folha de S.Paulo, 12 abr. 2019. Disponível em: https://www1.folha.uol.com.br/ poder/2019/04/caso-danilo-gentili-mobiliza-humoristas-e-gera-debate-sobre-liberdade-de-expressao.shtml. Acesso em: 20 set. 2019. 
